\title{
Interlocuções entre Psicologia e Direitos Humanos: práticas interventoras
}

\author{
Dialogues between Psychology and Human Rights: intervening \\ practices \\ http://dx.doi.org/10.5007/2178-4582.2013v47n2p198
}

\section{Rafael de Oliveira Rodrigues e Soraia Georgina Ferreira de Paiva Cruz}

Universidade Estadual Paulista-Assis, Assis/SP, Brasil

\begin{abstract}
A presente pesquisa-intervenção foi desenvolvida junto a adolescentes de um estabelecimento de atendimento à infância e adolescência consideradas de risco pessoal e social, situada numa cidade no interior do Estado de São Paulo. As práticas de atendimento que encontramos no estabelecimento em questão visam à prevenção de crianças e adolescentes que poderiam se tornar delinquentes e futuros marginais, pois são selecionados dentre as famílias mais pobres da periferia da cidade em que está localizada a Instituição. Nossa prática psicológica aqui relatada, entretanto, foi pensada e colocada em prática com a discussão sobre Direitos Humanos e Cidadania que visa afirmar aquilo que é considerado desvio à norma, abrindo espaços para a diferença na relação com a alteridade e para a afirmação política desses corpos no cenário urbano em que estão inseridos.
\end{abstract}

Palavras-chaves: Psicologia; disciplinarização; direitos humanos.
This intervention research was developed with adolescents of an establishment of care for children and adolescents considered at personal and social risk, in a city located in the state of São Paulo. The care practices found in the mentioned establishment are aimed at $\square$ prevention $\square$ of children and adolescents who could become offenders or future criminals, since they are selected from the poorest families in the outskirts of the city where the institution is located. Our psychological practice reported here, however, was conceived and put into practice from the discussion on Human Rights and Citizenship which aims to affirm what is considered deviation from the norm, opening spaces for the difference in relation to otherness and to the policy statement of these bodies in the urban setting within which they are inserted.

Keywords: Psycology; disciplining; human rights.

\section{Introdução}

A presente pesquisa-intervenção foi desenvolvida junto a adolescentes de um estabelecimento de atendimento à infância e adolescência consideradas de risco pessoal e social, situada numa cidade no interior do Estado de São Paulo. A referida entidade constitui-se atualmente como uma Organização Não-Governamental - ONG, possuindo caráter filantrópico, assistencialista e caritativo, com forte cunho religioso, sendo mantida por parcerias estatais e com algum auxílio da comunidade local.

Essa ONG foi fundada no início da década de 1970 por um sacerdote católico que se propunha a oferecer um espaço para as crianças e adolescentes se ocuparem com cursos pré-profissionalizantes, esportes e reforço escolar, a fim de evitar que essa população ficasse vagando pelas ruas, devido à crença que a rua era a $\lessdot$ escola do mal $\square$ (FREI, s/d). 
Entretanto, deve-se considerar também o contexto social e político da fundação do referido estabelecimento. A entidade nasceu no bojo da ditadura militar e do Ato Institucional $\mathrm{n}^{\circ} 5$, sendo que o aparelho estatal incentivou a criação desse modelo de estabelecimento, bem como de programas de educação voltados para crianças e adolescentes, cuja finalidade seria evitar que se tornassem futuros delinquentes e/ou marginais.

Sob essa perspectiva, as práticas de atendimento que encontramos no estabelecimento em questão visam à $\lceil$ prevenção $\square$ das crianças e adolescentes que tenham algum potencial para se tornarem delinquentes e futuros marginais, pois, conforme se acredita, essa potencialidade à marginalidade e ao crime repousa sobre a noção de que, sendo selecionados dentre as famílias mais pobres da periferia da cidade em que a entidade está localizada, o não-favorecimento econômico aliado ao contexto social da periferia, formaria adolescentes propensos a diversas formas de violência e criminalidade.

Segundo a noção de que essa população seria $\square$ naturalmente $\square$ propensa ao crime, o público-alvo atendido tem pouca idade, devido à crença de que, quanto mais cedo a população é atendida, mais cedo será "retirada" da vida do crime e das práticas marginalizadoras. Desse modo, a população atendida pela ONG é, prioritariamente, de crianças e adolescentes do sexo masculino e feminino, com idades de 07 à 17 anos. Além disso, é, de modo geral, composta por negros e pardos $\square$ o que reforça a tese de exclusão racial naquele município, uma vez que os negros ainda estão excluídos economicamente e relegados à condição de criminosos em potencial $\square$

De acordo com Jacques Donzelot (2001), a expansão das profissões ligadas ao trabalho social, como assistentes sociais e educadores especializados, que se deu a partir da década de 1970, vem constituindo a figura da criança e adolescente $\square$ de risco $\square$ ou seja, esses especialistas passam a relacionar contexto familiar e social com a virtual delinquência. Uma criança oriunda das camadas mais pobres da sociedade e da família considerada desestruturada teria, de acordo com esses estudos, o perfil do “(...) pré-delinquente, [ou seja] essa criança [encontra-se] em perigo de se tornar perigosa" (DONZELOT, 2011, p. 92).

Nesse sentido, apregoa-se, na Instituição, a utilização de práticas pedagógicas disciplinadoras, de autoritarismo, higienismo e tutela, a fim de administrar as virtualidades do comportamento humano, corrigindo os comportamentos desviantes, bem como recompensando aqueles sujeitos considerados adequados $\square$ às normas sociais e institucionais.

Segundo o Relatório do Estabelecimento (1999), as crianças e adolescentes ali assistidos:

(...) apresentavam-se em situação de risco pessoal e social, ainda que não em nível extremo, mas muito provavelmente poderiam atingi-lo, uma vez que estavam inseridos em um contexto familiar e social cuja realidade englobava a drogadição, o alcoolismo, a prostituição e a criminalidade conforme as estatísticas mostravam (RELATÓRIO... 1999). 
Podemos perceber nesse discurso, que emana da própria Instituição, uma associação entre pobreza e criminalidade, bem como uma ênfase no contexto familiar como determinante de uma possível delinquência.

Observamos que essas concepções e práticas correntes são responsáveis pela manutenção de uma política de atendimento que não propicia que esta população experimente outros lugares e possibilidades de vida, já que essa política de atendimento só reafirma o preconceito, a vitimização, os processos de estigmatização e exclusão social, tomados como inerentes às camadas pobres da sociedade brasileira.

Como tentativa de promover uma resistência a essa ideia que parece ganhar força nos tempos atuais, iniciamos uma problematização desses processos há vários anos dentro da Instituição, onde existe o desenvolvimento de uma Análise Institucional. Nosso objetivo era dar visibilidade aos jogos de forças institucionalizadas, e passagem às produções instituintes, evidenciando práticas discursivas e não-discursivas enunciadas pelos funcionários, pais, crianças e adolescentes.

A Análise Institucional indica uma prática política que, por meio de um dispositivo analítico de enunciação, dá visibilidade a várias forças em jogo no campo social. Dessa forma, enquanto teoria/prática e método, permite-nos dar visibilidade aos jogos e redes de poderes (práticas de controle e tutela, gestão e disciplinarização dos corpos), e saberes (educacionais, psicopedagógicos, psicológicos entre tantos outros) que se conectam no sentido de produzir a homogeneização das subjetividades.

No entanto, com a Análise Institucional em curso, e munidos dos dados afetivos-teóricos e práticos que essa ferramenta proporciona, notamos que existem movimentos virtuais de ruptura com o processo de subjetivação homogêneo, que derivariam dessas formas de assujeitamento inerentes à idéia de disciplina. Nesse sentido, investimos no campo grupal para que ele se tornasse um dispositivo de afirmação das rupturas e linhas de fuga, numa tentativa de romper com a norma instituída, libertando-se as formas de subjetivações para as $\square \mathrm{n} \square$ possibilidades.

\section{Dispositivo de ruptura com a norma instituída}

Na década de 1990, criamos uma modalidade de atenção aos adolescentes denominada "Oficinas de Cidadania e Direitos Humanos", visando operar uma desconstrução de uma prática que encontrava-se instituída nesse estabelecimento e que consideramos psicologizante.

Nossa prática problematiza o paradigma científico da Psicologia (historicamente constituído e imbuído da racionalização Iluminista), o qual tem se revelado como uma tecnologia eficaz de adestramento e ajustamento de sujeitos ou grupos diante da realidade social. Neste sentido, esse paradigma não é afeito a diálogos que interroguem seus registros de enunciados de verdade pretensamente universais. Esta perspectiva psicologizante afirma o mundo intrapsíquico desconectado daquilo que se conceitua mundo externo (leia-se a 
história, o social, o político); o sujeito que emerge dessas concepções é aquele aprisionado às leis do inconsciente, que governam o seu comportamento, mas que ele próprio desconhece as verdadeiras razões para seus atos.

Fabrica-se, dessa forma, gradativamente, o mundo interior, e o sujeito é levado a abrigar-se em sua intimidade, em suas emoções, em seus sentimentos; o voltar-se para si próprio numa espécie de narcisismo nunca alcançado. $\mathrm{O}$ indivíduo, assim subjetivado, usará seu tempo para decifrar a si mesmo, ou seja, exercitará a prática do autoconhecimento e da busca da autoestima. É então propagado que o sujeito, fazendo essa trajetória, encontrará o seu verdadeiro $E U$, encapsulando ainda mais a vida privada em detrimento da dimensão pública. Nessa lógica, produz-se um indivíduo assujeitado às normas, mas maximizadas em sua utilidade no processo vigente do capitalismo, ou seja: corpo obediente e produtivo, tal como nos adverte Michel Foucault (1987).

Nossas leituras em relação à Psicologia, utilizando as ferramentas teóricas de Michel Foucault, Gilles Deleuze e Regina Benevides, nos põem a interrogar os regimes de verdade tão propagados pelas ciências, e colocam-nos a pensar uma Psicologia que afirme os desvios à norma, que afirme a diferença nos modos de existir, que considere o sujeito/coletivo como efeitos das relações de saber, de poder e da ética e que os agenciamentos solidários possam se atualizar nas manifestações de resistência e criação de linhas de fuga. Nesse sentido, potencializam-se as ações que priorizem as relações de alteridade e cidadania. Em outras palavras, que os princípios contidos na Declaração Universal dos Direitos Humanos promulgada em 1948 ganhem visibilidade.

Nosso trabalho tende a divergir do paradigma que transforma história de vida em dossiês, em classificações e patologizações da existência, por meio de certo modo de interpretação que, ao longo dos séculos, tem associado pobreza e criminalidade. Por meio de oficinas ${ }^{l}$ que acontecem no interior dessa Instituição, temos problematizado a questão dos Direitos Humanos e Cidadania, as quais teceremos algumas interrogações que acompanham o desenrolar do projeto.

Tomaremos, então, como princípio norteador o artigo primeiro da Declaração Universal dos Direitos Humanos (1948). O referido artigo diz: $\square(. .$. Todos os homens nascem livres e iguais em dignidade e direitos”. É com essa perspectiva de Direitos Humanos, inalienáveis aos homens, que nos deparamos numa sociedade que criminaliza os pobres e os coloca como responsáveis pela sua própria miséria. Além disso, essa condição é aliada de um julgamento que eles próprios acabam por adotar: são incompetentes, indignos e fracassados diante de um mundo absorvido e controlado pelas práticas de mercado, em que se glorificam a competição e a individualidade. De acordo com Cecília Coimbra:

Deleuze afirma que os direitos humanos - desde suas gêneses - têm servido para levar aos subalternizados a ilusão de participação, de que as elites

${ }^{1}$ Essas oficinas serão mais detidamente tocadas no decorrer deste artigo. No entanto, cabe frisar que os autores deste artigo são compostos pela docente supervisora responsável pelo estágio curricular oferecido ao curso de Psicologia, assim como de um doutorando do Programa de Pós-Graduação em Psicologia, e ex-estagiário dessas oficinas. 
preocupam-se com o seu bem-estar, de que o humanismo dentro do capitalismo é uma realidade e com isso confirma-se o artigo primeiro da declaração de 1948 (...) (COIMBRA, 1999, p. 3).

Dessa forma, os direitos são negados às parcelas pobres que, criminalizadas, $\square$ (...) foram produzidas para serem vistas como $₫$ sub-humanas $\square$, como não pertencentes ao gênero humano $\square($ COIMBRA, 1999 p. 4). Sob essa perspectiva, tais direitos seriam associados às classes sociais, assegurado às elites. Aos segmentos pobres da sociedade são direitos: o da miséria, de morte e perdas (COIMBRA, 1999, p. 11).

Ainda de acordo com Coimbra, em seu texto publicado em 1994, intitulado $\square$ Cidadania e Processos de Inclusão e Exclusão Social: A Construção da Identidade $\square$, encontramos uma problematização dos Direitos Humanos propagados na humanidade. A autora parte da premissa de que a cidadania deve estar presente em todos os campos sociais, assim como os deveres e direitos. Esses direitos têm sido pouco garantidos às classes pobres, sendo reduzindo aos meios assistencialistas e paternalistas, enquanto que, cotidianamente, os deveres são amplamente cobrados (voto, impostos, condutas, entre outros). Populações inteiras (pobres) são deixadas à margem social e vão se consolidando no panorama social como exploradas e vitimizadas, as quais compõem territórios de risco; e, por mais que pratiquem movimentos políticos contestatórios, não têm êxito na garantia de seus direitos.

Para discutirmos essas questões dos Direitos Humanos e Cidadania é necessário dizer que o exercício do poder permeia o tecido social, ou seja, atravessa o conjunto de cidadãos de determinadas nações. Nesse sentido, partimos do pressuposto de que o poder não se centraliza e, num regime democrático, este princípio garante a qualificação da pluralidade dos sujeitos em suas participações políticas. Tornam-se legítimos os atos políticos que promovem problematizações, contestações, rebeldias que produzem novas relações de poder, novas relações de força, novas formas de sublevação e, desta forma, instigam uma construção histórica não mais de forma linear, e sim uma história que é criada através de rupturas.

André Duarte, analisando as discussões de Hannah Arendt, afirma que esta autora entenderá a política como um fenômeno importante, pois nele há a "(...) instauração coletiva da novidade" (DUARTE, 2004, p. 38). Sob essa perspectiva, Duarte argumenta que é resgatada a capacidade do homem de atuar no espaço público, e, buscando em Arendt uma aliada, sustenta que esse ato político afirma um amor pelo mundo, pelas coisas do mundo.

Nesta prática de cuidado para com a coisa pública, para com as coisas do mundo, nossa visão embaraça-se, pois sabemos que milhares de pessoas não têm acesso a bens culturais, materiais, simbólicos, mesmo aqueles garantidos pela lei. Essa massa é considerada por Foucault (2005) como "homens infames $\square$, por Bauman (2005) como $\square$ vidas desperdiçadas $\square$, e por Agamben (1998) $\sqsubset$ como vida nua $\square$ Essa massa nomeada por meio de diferentes conceitos tem algo em comum: ser dejeto humano, vida da qual o capitalismo $\checkmark$ vampirizou $\square$ toda a potência e agora a tornou $\square$ lixo $\square$ 
André Duarte (2004, p. 39) afirma, ainda, que a ciência, a tecnologia, a democracia de massas garantiriam a maior felicidade possível para o maior número de pessoas. Neste sentido, haveria nisso um paradoxo na democracia: milhares de pessoas às quais a promessa de felicidade reservou não a sua concretização, mas, ao contrário, o limbo da história, a margem social, sem valor algum, sem direito nenhum.

Agamben (1999, p. 152) problematiza a questão de que a política, na modernidade, se transformou em biopolítica, na qual cidadãos são reduzidos à categoria de $\square$ vida nua $\square$, passível de serem descartados e exterminados sem que ninguém seja penalizado pelo crime. $\mathrm{O}$ autor aponta, ainda, para o fato de que se as massas humanas forem impossibilitadas de terem voz e um lugar no mundo o projeto democrático cederá vez aos regimes totalitários.

Menos fatalistas que Agamben, Foucault (2003) e Castell (1987) afirmam que quando a vida é tomada como alvo da biopolítica, ela se torna algo a ser gerido, administrado, calculado e normatizado em função de explicações e efeitos de verdade biológicos. É essa vida que, agora, também será regulada juridicamente pelas leis que irão modular formas inéditas de controle social e tutela.

Coimbra argumenta que para sair desse $\square$ (...) lugar de legitimação do não exercício da cidadania" (1994, p. 7), é necessário desnaturalizar os saberes instituídos, quebrar a hegemonia do pensamento científico que desqualifica e desfertiliza $\square$ todos os outros saberes, criar novas ferramentas de lutas, assim como produzir conceitos guerrilheiros que desmontem as lógicas capitalísticas.

Assim, estamos atentos à história de nosso país que nos aponta para constantes práticas de violação dos direitos humanos, mesmo com o término da ditadura militar. Esperava-se, com a promulgação da Constituição em 1988, uma mudança significativa na preservação de direitos e criação de estratégias para seu cumprimento, e um novo olhar sobre as pessoas (principalmente sobre aquelas mais desfavorecidas economicamente) e sobre seus direitos civis e políticos. Mas o que se segue é um paradoxo entre o discurso e a prática, em que o direito passa a ser uma ferramenta utilizada pelas elites-especialistas, ficando praticamente inacessível aos estratos mais pobres da população. Segundo Marilena Chaú, as leis, os direitos seriam: $\square$ (...) uma concessão regulada e periódica da classe dominante às demais classes sociais, podendo ser-lhes retirada quando os dominantes assim o decidirem $\square$ (CHAUÍ, 1986 apud COIMBRA, 1994, p. 6).

\section{Breve memória da invenção dos direitos}

(...) Até quando você vai ficar usando rédea? Rindo da própria tragédia? Até quando você vai ficar usando rédea Pobre, rico ou classe média? Até quando você vai levar cascudo mudo? Muda, muda essa postura. Até quando você vai ficar mudo? 
Muda que o medo é um modo de fazer censura (...) (Gabriel $\mathrm{O} \square$ Pensador).

Coincidindo historicamente com uma concepção de mundo e de sociedade centrada no indivíduo, e articulados com o projeto moderno de constituição do sujeito, os Direitos Humanos se consolidaram a partir de uma revolução política em que as ideias de igualdade, liberdade e fraternidade $\square$ bandeira levantada pela Revolução Francesa, em $1789 \square$ foram incorporadas ao discurso burguês.

Segundo Plastino (2000), no processo de formação da doutrina sobre Direitos Humanos, emergem os direitos humanos de $\llbracket$ primeira geração $\square$, caracteristicamente direitos civis e políticos, os quais possibilitaram a ascensão social da burguesia a partir de uma limitação do poder estatal. Posteriormente, surgem os direitos sociais e econômicos, os de $\llbracket$ segunda geração $\square$ que por sua vez dizem respeito à obrigação da sociedade e do Estado de garantir o acesso aos bens e serviços necessários a uma vida digna.

Para Guareschi et al. (2000), diferentes momentos históricos forjaram os Direitos Humanos. Durante a Guerra Fria, criou-se uma dicotomia em relação a tais direitos em que, enquanto no bloco capitalista foram enfatizados os direitos civis e políticos, que se configuram como individuais, no bloco socialista, priorizaram-se os aspectos sociais, econômicos, coletivos e culturais. Tal dicotomia parece ter perdido força no contexto da realização da primeira Conferência Mundial dos Direitos Humanos das Nações Unidas, ocorrida em Teerã em 1968, em razão da noção de "integralidade" dos Direitos Humanos, haja vista que todos eles são fundamentais para o exercício da cidadania. Assim, o capitalismo se apropriou dos Direitos Humanos coletivos, voltados às questões sociais, econômicas e culturais, com vistas à sua universalização.

Nossas práticas psicológicas, que se compõem com as discussões sobre Direitos Humanos e Cidadania, visam afirmar aquilo que é considerado desvio à norma, abrindo espaços para a diferença na relação com a alteridade e a afirmação política desses corpos no cenário urbano. Dessa forma, é oferecido no curso de Psicologia um estágio curricular cujo tema é garantir uma problematização da interface entre Psicologia e Direitos Humanos, além de pautar práticas que objetivam a conexão e o agenciamento com novas estéticas contemporâneas e movimentos de resistência aos modos de subjetivação capitalísticos aqui descritos. Desse estágio, nasceram as intervenções nos formatos de oficinas semanais, cujos responsáveis são alunos matriculados no $4^{\circ}$ e $5^{\circ}$ anos de Psicologia, a saber: Oficina de Flauta-doce e Sensibilização Musical, Oficina de Capoeira Angola: uma desconstrução do corpo, Oficina de Fanzine e Leitura, Oficinas Literárias, Oficinas de Cartunismo, Oficina Dança (en) Cena, Oficina de Cidadania e Direitos Humanos.

Essas oficinas, sempre coordenadas pelos próprios alunos que, em dupla, ficam responsáveis por esses encontros, tem duração de 3 a 4 horas por encontro. O público-alvo varia conforme o interesse das crianças e adolescentes assistidos pela ONG e são supervisionados semanalmente pela docente res- 
ponsável, para garantir o sucesso das problematizações, a criação e potencialização das práticas disruptivas com a normalização vigente e fortalecimento do referencial teórico adotado. Como é no interior dessas oficinas que os movimentos de ruptura com os ditos normativos ocorre, passemos agora à uma breve descrição do que são essas oficinas.

\section{Oficinas de Flauta-doce e sensibilização musical}

Essas oficinas têm como objetivo apresentar novos modos de apreciação musical e sensibilizar o "ouvir" dos jovens para uma nova estética que se diferencie daquelas veiculadas pela máquina capitalística, que dissemina modelos hegemônicos de percepção e gostos musicais a partir da produção de subjetividades serializadas.

Dessa forma, experimentar a música enquanto possibilidade de ampliar universos de referência permitiria uma aproximação a planos sensíveis, os quais resistiriam aos \sons mercadológicos $\square$ que capturam a produção e a criação estética. Buscamos, nos encontros com a música, "engendrar subjetividades inusitadas" a partir de "agenciamentos de desejo estético" (GUATTARI, 1992), a fim de movimentar e expandir novas relações, novas conexões, novas suavidades e novas formas de habitar os territórios.

\section{Oficina de Capoeira Angola - uma desconstrução do corpo}

A oficina tem como objetivo passar conceitos básicos acerca da Capoeira Angola e aliá-los a um comprometimento ético-social, bem como a seu papel inclusivo, sem descartar o caráter cultural e múltiplo da Capoeira para dar, por meio dos movimentos e da musicalidade, matérias de expressão paras as intensidades vividas. A oficina também busca uma desconstrução das subjetividades massificadas, além de servir como fator de afetivação que aciona nosso corpo vibrátil, como valorização do coletivo, que propicia novos devires, novas intensidades e novos agenciamentos, enquanto potência que afirma as diferenças. Neste sentido não existe o sujeito que toca e o que joga capoeira: os afetos aí implicados desconstroem qualquer possibilidade de um poder hierárquico se sustentar.

\section{Oficinas de Fanzine ${ }^{2}$ e Leitura}

A proposta da presente oficina vem ao encontro com a criação de um espaço marginal através do qual discutiremos, junto aos adolescentes, temas que tenham afinidade com a contracultura. O Fanzine se abre como um dispositivo que, pelas suas características de ruptura, subversão de ideias e do próprio registro no qual ele se insere - a saber, meio de comunicação - permite

${ }^{2} \mathrm{O}$ termo fanzine designa: “(...) revista para fãs [...] sobre ficção científica, música e cinema [...] formado pela palavra fan "fã" e [...] magazine revista $\square$ (HOUAISS, 2001, p. 1307) 
abrir brechas na instituição na qual habitam os adolescentes que frequentam as oficinas. Assim, pode-se criar um plano que, através da literatura marginal - desenhos, poemas, música e discussões teoricamente fundamentadas - atualiza o potencial criativo, disruptivo e problematizador do adolescente em seu meio. Os encontros, neste sentido, agenciam conversações e resgates afirmativos da cultura específica daqueles adolescentes para conceber um conteúdo que ganhará forma e estilo na confecção dos fanzines.

\section{Oficinas Literárias}

Entendemos Literatura como um ato de criação e pensamento de ideias que emergem e operam inventando novos modos de sentir, agir, pensar. Mais que uma disciplina, a literatura aqui é também concebida como ato de criar no plano da Arte, ao utilizar-se de agregados sensíveis e compostos de sensações $\square$ os chamados afectos e perceptos $\square$ para traçar seu plano de pensamento. Assim, escrever é um ato no qual inventam-se possibilidades de passagem para a vida, desestabilizando organizações percepção-afecção-opinião dominantes, criando outras línguas para novos afectos e perceptos. Ato de resistência ao controle/disciplina e seus regimes de verdades. Ato de devir outro. As oficinas literárias acontecem no encontro de um grupo de crianças e adolescentes; há teatros espontâneos, criação de livros grandes e coletivos de histórias, poesias, músicas numa tentativa de escapar do modelo dissertativo e informativo presente no currículo escolar.

\section{Oficinas de Cartunismo}

O cartunismo é uma arte recente na história da humanidade. Tem como principais características o humor e a diversidade. É, ainda, uma forma narrativa constituída basicamente por imagens fixas que conduzem movimentos, pensamentos e informações. Portanto, agrega o desenho/imagem/foto/etc. a uma narrativa. A partir de nossa perspectiva ética-estética-política, o cartum remete à vida, pois é nela que se tecem as relações, os afetos, os valores e as culturas, de tal modo que a produção grupal, no encontro-oficina, se pauta por uma reinvenção de nossa postura frente ao mundo e às relações. Desse modo, a produção do cartum traz consigo a estratégia de reconciliação entre aquilo que se vive e sua potência de produção de novos discursos, conhecimentos e territórios existenciais, valorizados em sua íntima relação com a arte, enquanto vetor que possibilita novos regimes de sensibilidade: arte como criação e potência estética de sentir.

\section{Oficina Dança (en)cena}

Contrariando as formas que entendem a dança apenas sob uma perspectiva reprodutora de movimentos marcados que destituem do sujeito toda a sua 
biopotência, intentamos produzir uma ruptura nestes modos e, concomitantemente, a criação de um espaço que possibilite a tomada do corpo enquanto um "campo de experimentações", dando passagem à produção de uma nova estética de movimentação. Neste sentido, os movimentos corporais articulados às improvisações teatrais, músicas, literatura e comportamentos cotidianos naturalizados são agenciados por uma sensibilidade coletiva, impondo-se de tal maneira que se torne possível a virtualização de movimentos singulares e singularizantes nesse coletivo, cujos efeitos incitem a produção de $\square$ (...) novas maneiras de ser do ser que criam os ritmos, as formas, as cores, as intensidades da dança" (GUATTARI, 1992, p. 119). Invenções, pois, de novas expressões de dança contemporânea.

Esse processo possibilita a criação de novas sensibilidades e de novos modos de subjetivação que podem ser postos em circulação. Essa articulação entre Psicologia, Arte e Educação passa a funcionar como uma rede transdisciplinar produtora de sentidos fecundos e poéticos a corpos que antes se submetiam a expressões rígidas desencarnadas de afetos.

\section{Oficina de Cidadania e Direitos Humanos}

A partir da promulgação do Estatuto da Criança e do Adolescente (BRASIL, 1990), houve uma proliferação de instituições destinadas a defender os direitos da infância e adolescência, porém a invenção deste sujeito de direitos transforma-se em objeto de controle e tutela.

Para tanto, promovemos discussões que contemplam: o questionamento do instituído; o questionamento da naturalização de conceitos tais como o de cidadania e direitos humanos; a desmistificação da ideia de democracia tal como ela é veiculada por alguns partidos políticos, por uma grande parcela da mídia, e experenciada apenas como processo decisionístico por meio do voto; a desconstrução da ideia de imparcialidade e neutralidade da mídia, suscitando discussões acerca de sua força nos processos de subjetivação massificada; a problematização questões referentes ao sistema educacional que, de um modo geral, é reprodutor e mantenedor das desigualdades sociais.

(...) Muda, que quando a gente muda, o mundo muda com a gente. A gente muda o mundo na mudança da mente. E quando a mente muda, a gente anda pra frente. E quando a gente manda ninguém manda na gente (...). (Gabriel “O” Pensador).

\section{Conclusão}

Como pudemos acompanhar neste artigo, as oficinas, bem como a análise institucional que permeia todas as práticas ali instauradas, auxiliam os jovens a vislumbrar novas formas de se pensar a vida, suas implicações com as Instituições familiares, estatais, sociais, religiosas (entre outras), bem como pro- 
mover resistência às afirmações existências ancoradas em conceitos preconcebidos, que emanam das diversas instâncias em que os sujeitos percorrerem durante suas vidas.

As discussões no interior dos encontros, seja nas oficinas, seja fora delas, se transformam em conceitos guerrilheiros para esses jovens, emergindo assim movimentos de resistência à norma instituída; e também operam como linhas de fuga, já que entrariam na produção de novos modos de existência até então inéditos.

Como a prática adotada é a de fuga das linhas teóricas que criam dossiês, arquivos e diagnósticos sobre os sujeitos atendidos, e/ou da Instituição analisada, os efeitos das oficinas, bem como da Análise Institucional promovida na $\mathrm{ONG}$, são tênues e nunca registrados formalmente. Isso não quer dizer que não haja efeitos.

Nota-se que as crianças e adolescentes atendidos, por perceberem que não são alvo de preconceitos e estigmas historicamente construídos (como a ideia de que os negros são marginais; os mais pobres são propensos ao crime; a sexualidade é sempre heterossexista; entre outros) acabam trazendo questões que normalmente não são levadas à escola, como gravidez na adolescência, sexo e sexualidade, relação com drogas (lícitas e ilícitas), entre outros. Esses temas são, em geral, propostos pelas próprias crianças e adolescentes atendidas.

Ao mesmo tempo, nota-se que a vida, tomada em sua multiplicidade e desconectada com as normas vigentes, ganha novo status para esses jovens com sua inserção nas oficinas: muitos querem cursar uma Universidade; várias crianças e adolescentes repensam sua relação com o saber, com os outros e consigo mesmos, e compreendem que vale a pena viver a vida quando se afirma aquilo que potencializa esses corpos, desviando-se de ressentimentos e encontros instituídos e já capturados pela norma.

Tomando o grupo como dispositivo, acreditamos que há a possibilidade de afirmação dessas linhas pensadas como devires, que podem deslocar esses jovens dos modos de vida individualistas e intimistas para a produção de modos de vida da ordem do coletivo, do produtivo, descolando-se da ideia, tão cara aos sujeitos, de identidades pré-formadas.

\section{Referências}

AGAMBEN, Giorgio. O Poder Soberano e a Vida Nova. Homo-Sacer. Lisboa: Presença, 1984.

BALESTRERI, Ricardo Brisolla et al. Educando para a Cidadania. Os Direitos Humanos no Currículo Escolar. Porto Alegre: Editora Pallotti, 1992.

BAREMBLITT, Gregório. Compêndio de Análise Institucional e Outras Correntes. Rio de Janeiro: Rosa dos Tempos, 1994.

BAUMAN, Zygmunt. Vidas desperdiçadas. Rio de Janeiro: Jorge Zahar Editor, 2005. 
BRASIL. (Presidência da República). Lei no 8.069 de 13 de julho de 1990. Dispõe sobre o Estatuto da Criança e do Adolescente e dá outras providências. Diário Oficial da União Brasília, DF, 16.07.1990.

CASTELL, Robert. Gestão dos Riscos. Rio de Janeiro: Francisco Alves, 1987.

COIMBRA, Cecília Maria B. Direitos Humanos: Panorama Histórico e Atualidade. Palestra realizada no Seminário Psicologia e Direitos Humanos. Ribeirão Preto: USP, 1999. Disponível em: $\leq$ http://www.slab.uff.br/images/Aqruivos/textos_sti/Cec\%C3\%ADlia\%20Coimbra/ texto46.pdf $>$ Acesso em: 15 ago. 2013.

. Cidadania e Processo de Inclusão e Exclusão Social: a Construção da Identidade. Revista do Departamento de Psicologia. Rio de Janeiro, v. 6, nº 1 e 2, p. 1-8, 1994.

. Clínica e Política: Subjetividade e Violação dos Direitos Humanos. Rio de Janeiro: Instituto Franco Basaglia/Editora Tecortá, 2002.

COSTA, Jurandir Freire. Psicanálise e Contexto Cultural. Rio de Janeiro: Campos, 1989.

DALLARI, Dalmo de Abreu. O que são Direitos da Pessoa. São Paulo: Brasiliense, 1984.

DELEUZE, Gilles; PARNET, Claire. Diálogos. São Paulo: Escuta, 1998.

DONZELOT, Jacques. A Polícia das Famílias. 3. ed. Rio de Janeiro: Graal, 2001.

DUARTE, A.; LOPREATO, C. e MAGAlHÃES, M.B. (Orgs.) A banalização da violência: a atualidade do pensamento de Hannah Arendt. Rio de Janeiro: Relume Dumará, 2004.

FOUCAULT, Michel. Vigiar e Punir: Nascimento da Prisão.Petrópolis: Vozes, 1987.

. Estratégia, Poder-Saber. Rio de Janeiro: Forense Universitária, 2003 (Ditos e Escritos, v. IV).

. Ética, Sexualidade, Politica. Rio de Janeiro: Forense Universitária, 2004 (Ditos e Escritos, v. V).

FREI. Relatos coletados em conversas informais. s/d. Não publicado.

GUARESCHI, Pedrinho et al. Psicologia, Ética e Direitos Humanos. São Paulo: Casa do Psicólogo; Brasília: Conselho Federal de Psicologia, 2000.

GUATTARI, Félix. Caosmose: Um novo paradigma estético. São Paulo: 34, 1992.

HOUAISS, Antonio. Dicionário Houaiss da Língua Portuguesa. Rio de Janeiro: Objetiva, 2001.

ONU. (Organização das Nações Unidas). Declaração Universal dos Direitos Humanos. Adotada e proclamada pela resolução 217 A (III) da Assembléia Geral das Nações Unidas em 10 de dezembro de 1948 Disponível em: <http://portal.mj.gov.br/sedh/ct/legis intern/ ddh bib inter universal.htm $>$ Acesso em: 20 jan. 2012 
PLASTINO, Carlos Alberto. A Constituição do Sujeito Coletivo e a Questão dos Direitos Humanos. In: ACSELRAD, Gilberta. Avessos do Prazer: drogas, Aids e direitos humanos. Rio de Janeiro: Ed. Fiocruz, 2000. p,17-33

RELATÓRIO DO ESTABELECIMENTO. 1999 (mimeo, não publicado)

TELLES, Vera da Silva. Direitos Sociais. Afinal do que se Trata? Belo Horizonte: UFMG, 1999.

Submissão em: 12/09/2013

Revisão em: 26/10/2013

Aceite em: 05/02/2014

Rafael de Oliveira Rodrigues é Psicólogo formado pela Universidade Estadual Paulista Júlio de Mesquita Filho mestre em Psicologia e Sociedade e atualmente é doutorando pela mesma instituição. Foi bolsista do Programa de Doutorado Sanduíche no Exterior (PDSE) da CAPES, residindo na Cidade do México e estando vinculado à Universidad Autonoma Metropolitana (UAM), sucursal de Xochimilco no ano de 2013. Endereço para correspondência: Rua Platina, $n^{\circ}$ 1315. Vila Ebenezér. CEP: 19807-190. Assis/SP, Brasil.

E-mail: raover10@yahoo.com.br

Soraia Georgina Ferreira de Paiva Cruz é Professora Assistente da Universidade Estadual Paulista Júlio de Mesquita Filho, campus de Assis. Possui mestrado em Psicologia (Psicologia Social) pela Pontifícia Universidade Católica de São Paulo (1989) e doutorado em Educação pela Universidade Estadual Paulista Júlio de Mesquita Filho $\square(2001)$.E-mail: socruz@assis.unesp.br 